\title{
References
}

1. ItayA, K. and M. Ur, Clin. chim. Acta (Amsterdam) 14, 361 (1966). - 2. Fiske, C. H. and Y. Subbarow, J. biol. Chemistry 66, 375 (1925). - 3. Martin, J. B. and D. M. Doty, Analytic.
Chem., 21, 965 (1949). - 4. TAusskx, H. H. and E. Schorr, J. biol. Chemistry, 202, 675 (1953).
Drs. A. J. Bastiaanse Geldrop (Niederlande) St. Anna Hospital

\section{Automatisierung der Glucosebestimmung mit o-Toluidin}

\author{
Von K. LEYBold \\ Aus der II. Medizinischën Universitätsklinik und Poliklinik Kiel (Direktor: Prof. Dr. L. Weissbecker)
}

(Eingegangen am 12. April 1966)

Die Anpassung der Glucosebestimmung mit o-Toluidin an die tageszeitlich verschiedenen Anforderungen einer Klinik wird beschrieben. Blut wird in Mikroröhrchen in Trichloressigsäure durch hochtourige Zentrifugation in wenigen Sekunden enteiweißt, der Ủberstand vom Probennehmer des Autoanalyzers direkt über dem Sediment zur automatischen photometrischen Bestimmung entnommen. Wesentliche technische Merkmale sind ein zur Aufnahme von Mikroröhrchen veränderter Probenteller, das Fehlen des Dialysators und die Verwendung von säurefestem Siliconschlauch in der Pumpe und als allgemeinem Verbindungsschlauch im Autoanalyzer. Für Einzelbestimmungen kann eiweißfreier Uberstand aus den gleichen Probenröhrchen von Hand entnommen werden. Präzision und Empfindlichkeit der Methode, besonders im niedrigen Konzentrationsbereich, sind gut.

The determination of glucose with o-toluidine was adapted to the daily varied requirements of the hospital. Blood is deproteinised in a few seconds by treatment with trichloracetic acid in microcentrifuge tubes, followed by high speed centrifugation. The supernatant is taken directly from above the sediment by the crook of the autoanalyser, and the photometric determination then procedes automatically. The essential features of this technique are the modification of the sample plate to receive micro-tubes, the ommission of the dialyser, and the use of acid-resistant silicone tubing in the pump and generally for other connections. For individual measurements, deproteinised supernatant can be sampled from the same tubes for quantitative determinations by hand. The precision and sensitivity of the method are good, especially at low concentrations.

Die kolorimetrische Bestimmung der Blutglucose mit oToluidin nach HULTMANN (1) besticht durch ihre einfache Technik, gute Spezifität und Empfindlichkeit. Sie wurde mehrfach bearbeitet $(2,3,4)$. Testpackungen sind im Handel. ZENDER (5) hat die Methode an den Autoanalyzer angepaßt. Der Aufwand und die geringe Analysenfrequenz haben uns veranlaßt, diese Bestimmung im Autoanalyzer einfacher, schneller, rentabler und dabei empfindlich zu gestalten und sie unseren Klinikbelangen mit sehr unterschiedlichen zeitlichen und zahlenmäßigen Anforderungen anzupassen.

\section{Methodik}

\section{Prinzip}

Zunächst geben wir, wie für die Handmethode beschrieben, Kapillarblut in Trichloressigsäure. Dieses Gemisch liefert, in Mikroanalysenröhrchen wenige Sek. hochtourig zentrifugiert, ein festes Sediment und einen klaren Überstand. Wahlweise können wir nun, wie üblich, einen Teil des Überstandes zur Glucosebestimmung von Hand mit o-Toluidin versetzen, erhitzen und nach kurzer Kühlung im Photometer analysieren (bei wenigen Bestimmungen) oder direkt vom Probennehmer des Autoanalyzers aus den gleichen Röhrchen abhebern lassen (bei vielen Bestimmungen), wobei die Dialyse eingespart wird.

\section{Geräte und Cbemikalien}

Autoanalyzer (Ștandardaussührung mit Zwischenspülung ohne Dialysator mit Filter $625 \mathrm{~nm}$ und Nockenscheibe zur Entnahme von 40 Proben pro Std.) der Fa. Technicon, Chertsey/England, mit selbstgefertigter, $1 \mathrm{~cm}$ dicker Plexiglasscheibe auf dem Probenteller zur Aufnahme der Mikroröhrchen (s. u.) in randständigen Löchern von $11 \mathrm{~mm}$ Durchmesser und Siliconschlauchergänzung (s. Fließschema).

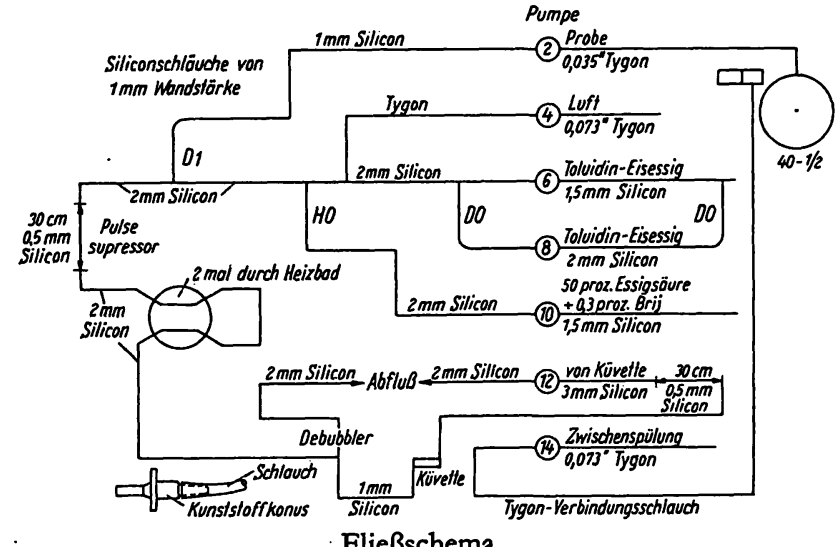

Fließschema

Mikrozentrifuge und Mikroanalysentöhrchen aus Polypropylen der Fa. Eppendorf-Gerätebau, Hamburg.

Siliconschlauch von $1 \mathrm{~mm}$ Wandstärke mit verschiedenem Innendurchmesser (Abb.) der Fa. Rehau Plastics GmbH in Rehau/ Bayern. Die Pumpenschläuche aus Silicon sollen $15,5 \mathrm{~cm}$ lang sein; sie; werden mit Kunststoffverbindungsstücken mit Rekordkonus der Fa. Braun/Melsungen in den beiden Schlauchhalterungen der Schlauchpumpe fixiert (Abb.), die in ihren äußeren Löchern befestigt werden.

Gerät zur Kapillarblutentnahme.

Trichloressigsäure p. a., o-Toluidin puriss. p. a. von Fluka.

Essigsäure reinst, 99-100 proz., Thioharnstoff p. a., Benzoesäure p. a., Brij 35 von Technicon.

$\mathrm{D}(+)$ Glucose $\cdot \mathrm{H}_{2} \mathrm{O}$.

\section{Lösungen}

3 proz. Trichloressigsäure ${ }^{1}$.

Toluidinreagens ${ }^{1}$ ): in 1 / Eisessig werden $3 \mathrm{~g}$ Thioharnstoff gelöst, dann $100 \mathrm{~m} l o$-Toluidin zugefügt (braune Flasche).

1) Die Fa. E. Merck, Darmstadt, liefert Fertigreagenzien. 
50 proz. Essigsäure mit $0,3 \%$ (v/v) Brij,

Glucosestammlösung $1,0 \mathrm{mg} / 100 \mathrm{ml} 0,2$ proz. Benzoesäure,

Glucosestandardlösungen $50,100,150,200,300,400$ und $500 \mathrm{mg} /$

$100 \mathrm{~m} /$ in 0,2 proz. Benzoesäure.

\section{Ausführung}

In Mikroröhrchen wird $1 \mathrm{~m} / \mathrm{TCE}^{2}$ ) pipettiert. Nach Zugabe von $0,1 \mathrm{~m} /$ Blut (Liquor, usw.) wird geschüttelt und 15 Sek. in der Mikrozentrifuge mit 17000 U/Min. geschleudert. Dann kommen die Röhrchen nebst ebenso zubereiteten Verdünnungen der Standardlösungen (Eichkurve) in den Probenteller. Von den TCE-Verdünnungen der Standardlösungen stellt man sich eine Menge her, die etwa eine Woche reicht. Danach werden neue Verdünnungen angesetzt, denn die Meßwerte für Glucose in TCE nehmen allmählich zu. Das Fließschema für Probe und Reagenzien ist im Detail in der Abbildung wiedergegeben. Ausgewertet wird mit der Universalschablone.

\section{Charakteristik der Methode und Diskussion Technische Durcbfübrung}

Durch den Plexiglasaufsatz auf dem Probenteller kann die enteiweißte Probe direkt aus den Mikroröhrchen über dem Sediment abgehebert werden. Das Ergebnis liegt etwa acht Minuten nach der Probenentnahme vor. Läuft der Autoanalyzer gerade für eine andere Analyse, so werden dringende Glucosebestimmungen bei gleicher Enteiweißung durch Abpipettieren von $0,5 \mathrm{ml}$ Überstand von Hand gemacht, ebenso alle Bestimmungen am Nachmittag und im Bereitschaftsdienst. Wir versetzen dann den Überstand mit $2,5 \mathrm{~m} /$ Touidinreagens, kochen 8 Min., kühlen 4 Min. und photometrieren danach mit Filter $578 \mathrm{~nm}$ in $1 \mathrm{~cm}$-Küvetten.

Durch die Eiweißfällung entfällt der Dialysator. Das Heizbad wird zweimal durchlaufen. Optimaler Küvettendurchfluß kann mit dem 3 mm-Pumpenschlauch einreguliert werden; kommen zuviele Luftblasen, so wird er etwas gekürzt, wodurch sich sein innerer Durchmesser und damit der Küvettendurchfluß verringert. Wir verwenden Blende 7 am Reference-Filter. Pro Stunde werden etwa $175 \mathrm{~m} /$ Toluidinreagens verbraucht. Um käufliches Toluidinreagens (z. B. Merckotest) vet-

2) $\mathrm{TCE}=$ Trichloressigsäure. wenden zu können, mischen wir durch einen gesonderten Pumpenschlauch das Brij in 50proz. Essigsäure zu. Fluorid stört die Bestimmung nicht. Mit der Toluidinreaktion können Unklarheiten bei der polarimetrischen Urinuntersuchung manchmal beseitigt werden. Zweimal haben wir nach Makrodexinfusionen eine störende Trübung festgestellt.

\section{Kosten}

Die Materialkosten (ohne Personal und Erstanschaffung) belaufen sich auf 0,18 DM pro Bestimmung. Eine Assistentin, die durchschnittlich 120 Glucose- und 30 Harnstoff bestimmungen täglich im Autoanalyzer durchführt, ist zu etwa $60 \%$ ausgelastet. Der billige Siliconschlauch wird etwa drei Wochen in der Pumpe belassen.

\section{Präzision, Ricbtigkeit, Empfindlicbleeit}

Anhand eines bei $-18^{\circ}$ verwahrten Serumpools, von dem täglich eine kleine Menge zur Glucosebestimmung aufgetaut wird, haben wir aus den $z$.Z. vorliegenden 62 Bestimmungen Mittelwert und Standardabweichung (s) berechnet, ebenso aus 62 Bestimmungen des gleichen Pools, dem $200 \mathrm{mg} / 100 \mathrm{ml}$ Glucose zugesetzt sind. Ergebnis: Serum ohne Glucosezusatz: Mittelwert 100,7 $\mathrm{mg} / 100 \mathrm{ml}, \mathrm{s}=4,5 \mathrm{mg} / 100 \mathrm{ml}$; gleiches Serum mit Zusatz von $200 \mathrm{mg} / 100 \mathrm{~m} l$ Glucose: Mittelwert $300,1 \mathrm{mg} /$ $100 \mathrm{~m} l, \mathrm{~s}=11,6 \mathrm{mg} / 100 \mathrm{ml}$. Die zugesetzte Glucose wird also vollständig wiedergefunden. Wir haben Glucose ferner an einer Reihe von Kontrollseren bestimmt. In drei Fällen sind die Werte etwas niedriger als die angegebenen, in drei Fällen entsprechen sie diesen praktisch. Fortlaufende Bestimmungen an ein und derselben Lösung, auf viele Probentöhrchen verteilt, ergeben die Präzision des Autoanalyzers, da der Pipettierfehler entfällt. Bis zu $200 \mathrm{mg} / 100 \mathrm{ml}$-Glucose liegt s hietbei konstant bei $1,4 \mathrm{mg} / 100 \mathrm{ml}$. Die gegenseitige Beeinflussung der Bestimmungen ist zu vernachlässigen. Lediglich ein Wert von $50 \mathrm{mg} / 100 \mathrm{~m} /$ fällt um $10 \%$ zu hoch aus, wenn et auf einen Wert von $500 \mathrm{mg} / 100 \mathrm{~m} /$ folgt. Die Empfindlichkeit ist, besonders im niedrigen Konzentrationsbereich, sehr gut. Die Werte von 0 bis $250 \mathrm{mg} / 100 \mathrm{ml}$ nehmen den halben Skalenbereich ein. Über die Spezifität wird bei DuBowski (3) und ZeNDER (5) berichtet. Wahrscheinlich läßt sich auch die Glucosebestimmung mit Anilin-Eisessig (6) technisch in ähnlicher Weise durchführen.

\section{Literatur}

1. HultmanN, E., Nature (London) 183, 108 (1959): - 2. HyväRINEN, A. und E. A. NikkIrÄ, Clin. chim. Acta (Amsterdam) 7, 140 (1962). - 3. Duвowskr, K. M., Clin. chim. Acta (Amsterdam) 8, 215 (1962). - 4. Photometrische Methoden - Medizin, Fa. Eppen-
dorf-Gerätebau, Hamburg-Hummelsbüttel. - 5. ZENDER, R., Clin. chim. Acta (Amstetdam) 8, 351 (1963). - 6. Ammon, J., S. Dunker, H. Dirschunert und E. F. Pferffier, Internationales Technicon Symposium, Oktober 1965 in Frankfurt am Main.

Dr. Karl Leybold 23 Kiel Metz Str. 55-57 